\title{
EVALUATION OF FOUR LOCAL MATERIALS AS BACKFILL TO ACHIEVE A LOW EARTH ELECTRODE RESISTANCE
}

\author{
P.Y. Okyere ${ }^{1}$, G. Eduful ${ }^{2}$ and E. A. Frimpong ${ }^{1}$ \\ Department of Electrical/Electronics Engineering \\ ${ }^{1}$ Kwame Nkrumah University of Science and Technology, Kumasi, Ghana \\ ${ }^{2}$ Electricity Company of Ghana, P.O. Box 1980, Kumasi, Ghana
}

\begin{abstract}
In this study, the efficiency of materials available for free, namely palm kernel oil cake, tyre ash, wood ash and powdered cocoa shell, as conductive backfill for reducing earth electrode resistance was evaluated. Earth rod of 30-cm length and 14-mm diameter was installed for each backfilling material at a site and their performance compared with that of a reference earth rod also installed at the same site. The results show that tyre ash provides a stable earth electrode resistance in both dry and wet weather conditions and improves it to about $16 \%$.
\end{abstract}

Keywords: Earth electrode resistance, conductive backfill, critical resistance area.

\section{INTRODUCTION}

Earthing is used in electrical systems to ensure personnel and equipment safety. Low earth resistance is essential to meet electrical safety standards. The resistance value can vary from $10 \mathrm{ohms}$ for lightning protection to below 0.1 ohm for many sites where protective devices must operate in a very short time due to large fault currents involved (Reeves, 1990). When a driven rod is used as earth electrode, low earth electrode resistance is achieved in practice by using deep driven rods, or by using rods with increased diameter or with multiple rods. Low earth electrode resistance can also be achieved in practice by using chemical compounds or soil of lower resistivity as earth electrode backfill (Reeves, 1990, Carpenter et al, 1997, Furse).

The use of chemical compounds as earth electrode backfill provides a very effective method of dealing with high resistivity soil. It can give improvement in earth electrode resistance values up to 20\% (Reeves, 1990). In Ghana, it is common practice to use materials available for free instead of commercial chemical compounds as electrode backfill.

In this study, the efficiency of four materials commonly used as conductive backfill for lowering earth electrode resistance was investigated. The materials are palm kernel oil cake (PKOC), tyre ash, powdered cocoa shells (PCS) and wood ash. Results show that application of tyre ash as a conductive backfill can lower ground resistance by about $84 \%$ as obtained with commercial chemical compounds.

\section{Methodology}

Earth rod of 30-cm length and 14-mm diameter was installed for each backfilling material at a site. A study has shown that it suffices to limit 
the backfilling material to a critical resistance area very close to the ground rods (Okyere et al, 2006). The radius of the area referred to as critical resistance radius has been found to be about $40 \%$ of the length of the driven rod (Okyere et al, 2006). This critical area resistance method was applied in the backfilling of the driven rods. Earth resistance of each electrode was measured for a period of three months using the DET5/4R Digital Earth Tester. For the purpose of comparison, an earth rod without a conductive backfill termed reference electrode was also installed at the site. Additionally, laboratory analysis was performed on samples of the materials at the Soil Research Institute in Kumasi to determine their $\mathrm{pH}$ levels and water-holding capacities.

\section{RESULTS AND DISCUSSION}

The earth electrode resistances measured on a number of days spanning a period of three months are presented in Figures 1(a) and 1 (b). Figure 1(b) shows the readings taken on $15^{\text {th }}$ December, 2008 and $4^{\text {th }}$ January, 2009 some of which were exceptionally high and for that matter needed to be separated from the rest and drawn with a larger scale factor. The results of the laboratory analysis on the materials are given in Table 1. Earth electrode resistance is much influenced by the moisture content of soil. Therefore the rainfall during the period of investigation became of interest. Figure 2 shows the rainfall recorded from $1^{\text {st }}$ October, 2008 to $4^{\text {th }}$ January, 2008 by a weather station on Kwame Nkrumah University campus close to the experimental site.

The tyre ash was observed to have provided the lowest and most stable resistance during the entire period. Figure 3 shows the variation of the resistance with time. The reading taken on a day is expressed as percentage of the resistance of the reference electrode taken on the same day. The tyre ash is found to have given improvement in earth electrode resistance value up to about $16 \%$ in the wet season and further improvement of about $8 \%$ in the dry season. The palm kernel oil cake and the powdered cocoa shell offered significant reduction from $10^{\text {th }}$ October through $14^{\text {th }}$ November when there were a number of light and moderate rains. However from $22^{\text {nd }}$ November, 2008 through $4^{\text {th }}$ January, 2009 when the dry season set in, their resistances became very unstable, falling when there were light rains and soaring when there were no rains. There were days as shown in Figure 1.b when they produced resistance values many times greater than that of the reference electrode. These materials shown to have high water-holding capacity are found to

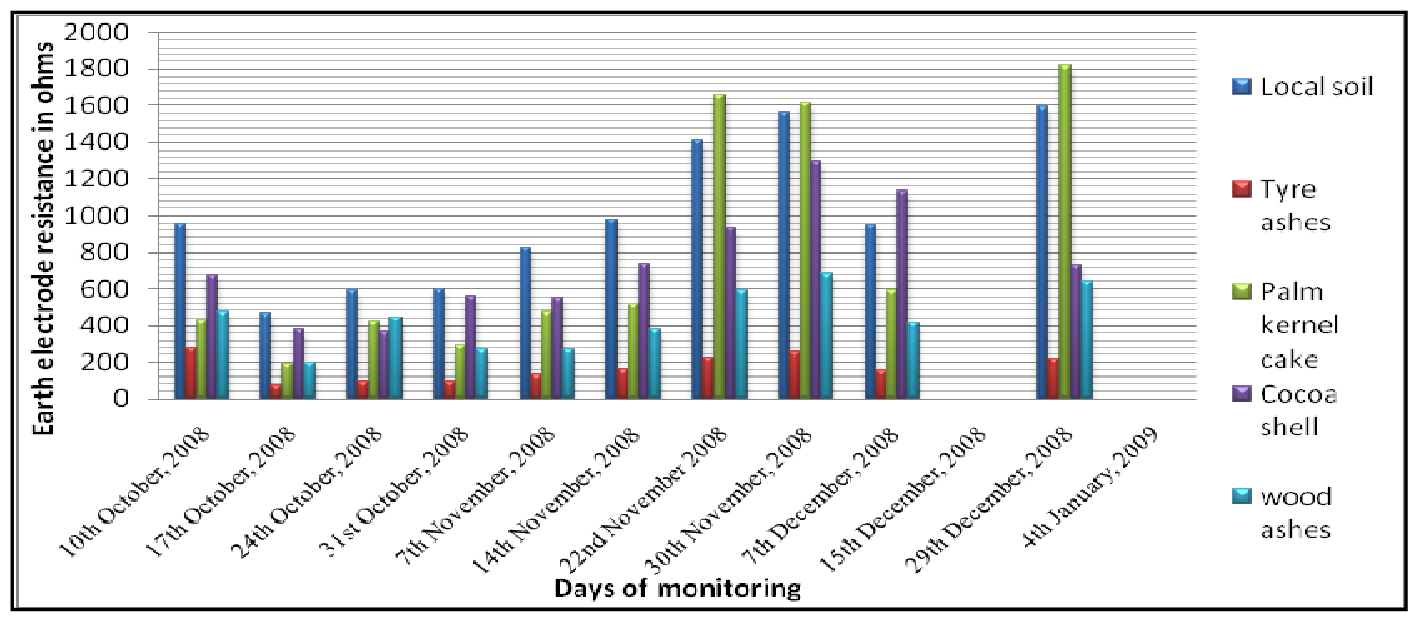

(a) 


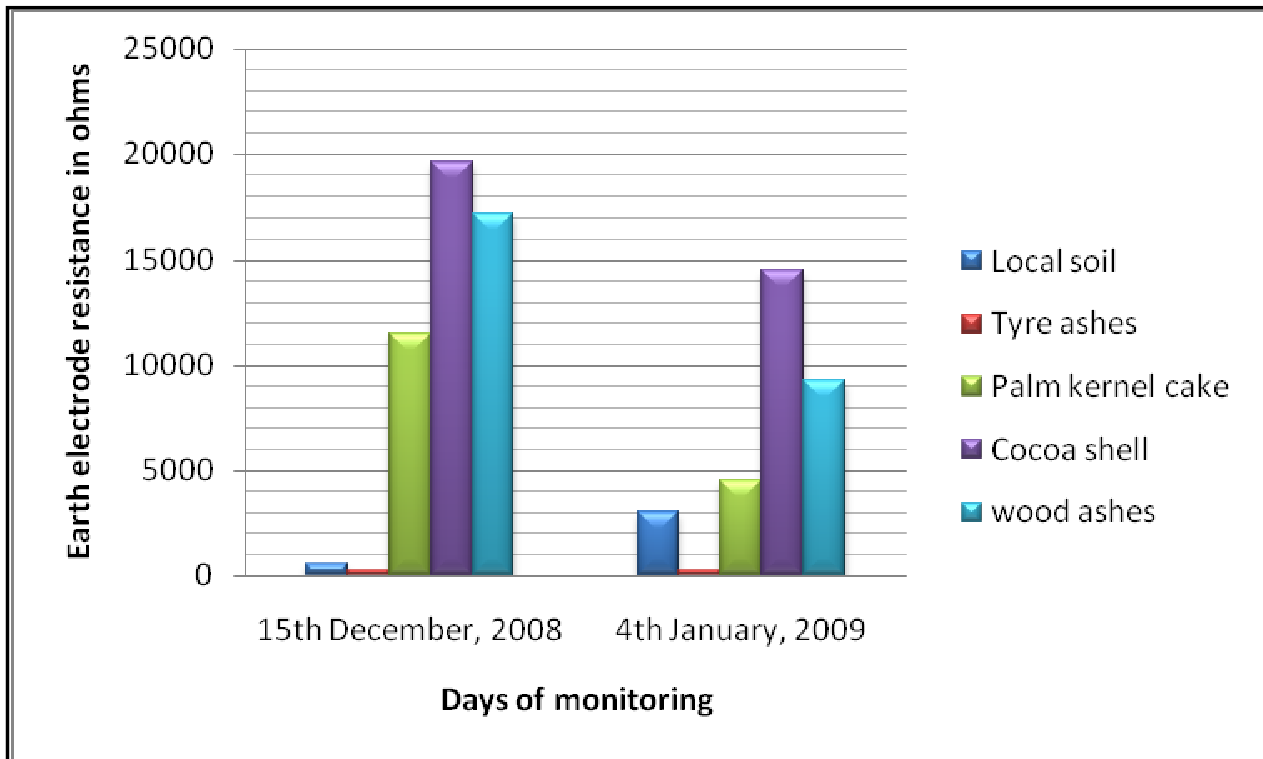

(b)

Fig. 1: Variation of resistances of earth electrodes with time

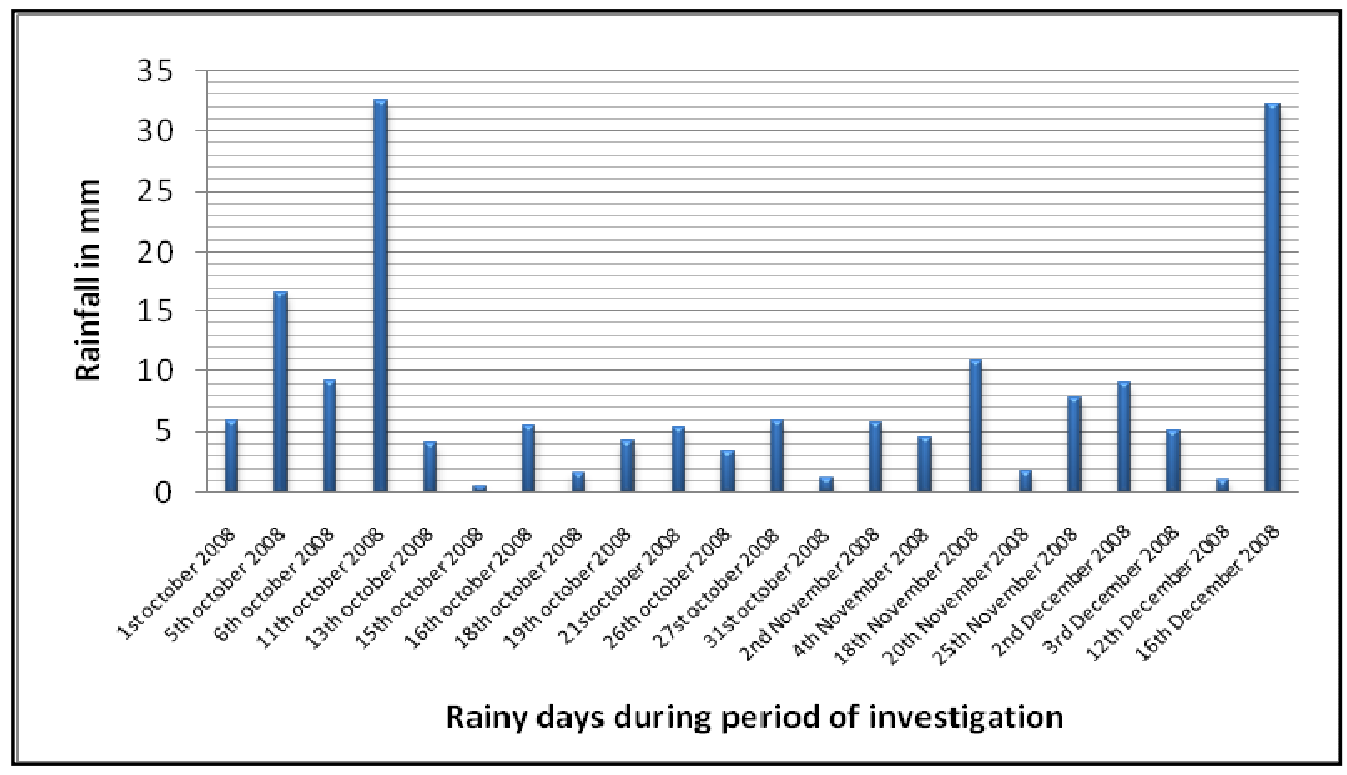

Fig. 2 Rainfall during period of investigation 
be effective in wet weather conditions and ineffective in very dry weather conditions. The wood ash, though relatively more stable, was also ineffective in the dry weather conditions. These three materials, namely, tyre ash, palm kernel oil cake and powdered cocoa shell could be of interest where earth electrode could be installed deep enough to reach the water table.

Soils have a $\mathrm{pH}$ range of 5-8 (Corrosionsource.com, 2009). The $\mathrm{pH}$ level of the tyre ash is found to be within this range. In this range, $\mathrm{pH}$ is generally not considered to be the dominant variable affecting corrosion rates. The $\mathrm{pH}$ levels of the three other backfilling materials, wood ash, powdered cocoa shell and palm kernel oil cake are very close although they are outside the $\mathrm{pH}$ range of $5-8$.

\section{CONCLUSION}

The efficiency of palm kernel oil cake, tyre ash, wood ash and powdered cocoa shells commonly used as conductive backfill for reducing earth electrode resistance in Ghana has been investigated. The study has revealed that the use of palm kernel oil cake, wood ash and powdered cocoa shells as backfills can result in low earth electrode resistance in the wet season but extremely high earth resistance in the dry season. The tyre ash on the other hand is effective in both wet and dry conditions. It can give improvement in earth electrode resistance up to $16 \%$. The tyre ash also has a $\mathrm{pH}$ level of 6.22 , which falls within the range of the $\mathrm{pH}$ of natural soil. Therefore, it is unlikely to cause damage to electrodes by corrosion.

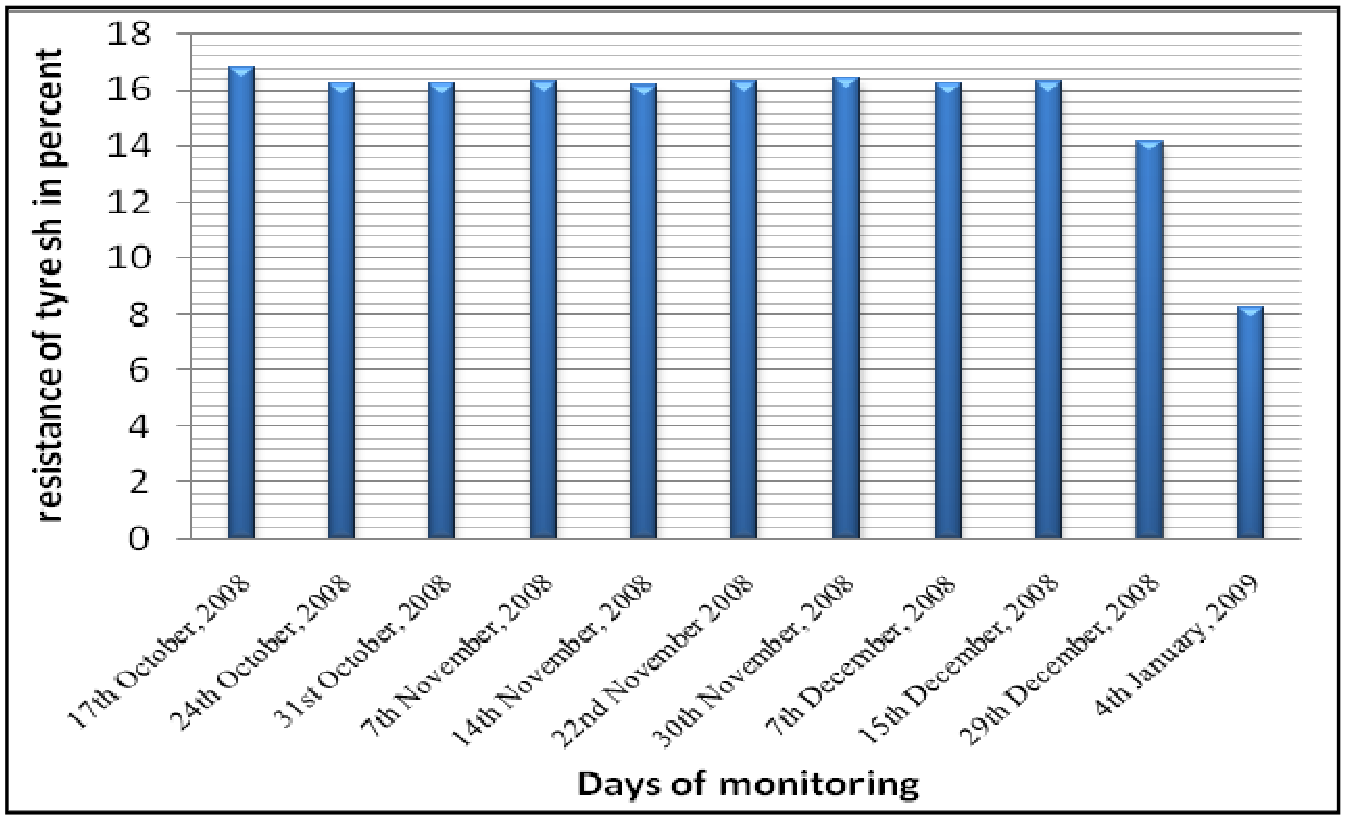

Fig. 3 Resistance of electrode with tyre ash as backfill in per cent

Table 1: Water-holding capacities and pH levels of local backfilling materials

\begin{tabular}{lcccc}
\hline & PKOC & PCS & Tyre ash & Wood ash \\
\hline $\mathrm{pH}$ & 4.51 & 4.25 & 6.22 & 8.99 \\
Moisture holding capacity & 102.35 & 337.52 & 70.59 & 17.96 \\
\hline
\end{tabular}




\section{REFERENCE}

Carpenter, R. B. Jnr., Lanzoni, J. A.(1997) Designing for a Low Resistance Earth Interface (Grounding), An LEC Publication.

Corrosionsource.com (2009). Soil variables retrieved from www.corrosionsource.com / technicallibrary/corrdoctors/Modules/Soil Corrosion/Variables.htm. Accesssed on $02 / 02 / 2009$.

Furse, W. J. and Co, Ltd, Consultants Handbook 'Recommendations for the Protection of Structures against Lightning', Wilford Road Nothingham, pp 40.
Okyere, P. Y. and Eduful, G.(2006), 'Reducing Earth Electrode Resistance by Replacing Soil in Critical Resistance Area', The International Journal of Modern Engineering, Vol. 6, No. 2.

Reeves, E. A. (1990), Handbook of Electrical installation Practice, Black Well Scientific Publications, pp $181-194$. 